\title{
Depressive and Anxiety Symptoms among Pediatric In-Patients with Dengue Fever: A Case-Control Study
}

\author{
Von Ralph Dane M. Herbuela 1®D, Ferdinand S. de Guzman ${ }^{2}$, Girly D. Sobrepeña ${ }^{3}$, \\ Andrew Benedict F. Claudio ${ }^{4}$, Angelica Cecilia V. Tomas ${ }^{5}$, Carmina M. Arriola-delos Reyes 5 , \\ Rachele A. Regalado ${ }^{6}$, Mariama M. Teodoro ${ }^{7}$ and Kozo Watanabe ${ }^{1,8, *}$ \\ 1 Graduate School of Science and Engineering, Ehime University, Bunkyo-cho 3, Matsuyama 790-8577, Japan; \\ herbuelavonralphdane@gmail.com \\ 2 Department of Family and Community Medicine, Infectious Diseases and Tropical Medicine, \\ San Lazaro Hospital, Manila 1003, Philippines; fdgzm06@gmail.com \\ 3 Pediatrics Department, Quezon City General Hospital, Quezon City 1106, Philippines; \\ sobrepenagirly@yahoo.com \\ 4 Office of Nursing Service, Pasay City General Hospital, Pasay City 1300, Philippines; \\ tomriddle_07@yahoo.com \\ 5 Department of Pediatrics, College of Medicine, University of the Philippines, Manila 1000, Philippines; \\ anggetomas@gmail.com (A.C.V.T.); minettedr@yahoo.com (C.M.A.-d.R.) \\ 6 Guidance Department, University of Santo Tomas-Angelicum College, Quezon City 1114, Philippines; \\ cheleregalado@gmail.com \\ 7 Counseling and Educational Psychology Department, De La Salle University, Manila 1004, Philippines; \\ mariamateodoro@gmail.com \\ 8 Biological Control Research Unit, Center for Natural Science and Environmental Research, \\ De La Salle University, Manila 1004, Philippines \\ * Correspondence: watanabe_kozo@cee.ehime-u.ac.jp
}

Received: 29 November 2019; Accepted: 17 December 2019; Published: 21 December 2019

check for updates

\begin{abstract}
Background: Psychiatric symptoms have been reported in adult patients with dengue fever (DF); however, information on pediatric patients remains inadequate. We sought to identify the prevalence and predictors of depressive and anxiety symptoms and identify other psychiatric symptoms among pediatric patients with DF. This case-control study involved pediatric in-patients $(n=225)$ who had clinical or serologic-confirmed DF and healthy school-based controls $(n=260)$. Participants completed the Revised Child Anxiety and Depression Scale (RCADS). Results: The prevalence of depressive $(13.3 \%)$ and anxiety $(34.2 \%)$ symptoms among pediatric patients with DF was significantly $(p<0.001)$ higher than that among controls $(3.5 \%$ and $16.2 \%$, respectively). Multiple linear regression analysis found that age, family history of $\mathrm{DF}, \leq 2$ days of hospitalization, myalgia, and arthralgia were predictors of increased depressive and anxiety symptoms among the patients. Further, $26.7 \%$ of pediatric patients reported irritability, agitation, visual hallucinations, and aggressiveness. Conclusion: Pediatric patients present depressive and anxiety symptoms whose levels were associated with social and clinical factors. However, whether these symptoms are present only during the infection or may still persist after recovery or are brought by children's adverse reactions to hospitalization are unknown, and thus, further studies are needed.
\end{abstract}

Keywords: dengue fever; depression; anxiety; pediatric psychiatry

\section{Introduction}

As the world's most rapidly spreading mosquito-borne disease, dengue fever (DF) causes approximately 50 million cases a year, putting an estimated 2.5 billion people at risk, especially 
children [1]. Its incidence has increased by 30 times in the last five decades [2] and is now prevalent in 128 countries [3]. It presents flu-like symptoms that include high-grade fever accompanied by headache, myalgia and arthralgia, nausea and vomiting, intense abdominal pain, rash, retro-/peri-orbital pain, bleeding, and low platelet count (thrombocytopenia), which can lead to acute organ failure, cardiomyopathy, encephalitis, profound shock, and death [1]. Recently, the number of studies reporting this virus to be neurovirulent has increased [4], associating it with neurological complications in patients with DF [5].

The most prevalent neurological disorder occurring during DF is encephalopathy [6]. Case study reports found that adult patients with DF exhibit delusions with auditory and visual hallucinations, agitation and psychotic symptoms and fears, agitation, irritable affect, psychosis, mania, and catatonia [7-14]. The link between these symptoms and DF infection have been thought to be the result of metabolic disturbances, direct tissue lesion, intercranial hemorrhage, cerebral edema and anoxia and hyponatremia [7,11,12]. Among the identified encephalopathies, depressive and anxiety symptoms were the most studied among adult patients with DF [15-18]. The prevalence of borderline and clinical depression and anxiety among adult patients with DF ranges from $60 \%$ to $81 \%$ [16,17]. During the acute phase, the majority (90\%) of patients exhibit thanatophobia or fear of death (90\%), and during the recovery phase (1 week after onset of DF), more than half (55\%) of patients develop fear of mosquitoes (55\%) [15,18]. Most importantly, the severity of DF symptoms such as fever, headache, myalgia, arthralgia, retro-/peri-orbital pain, and thrombocytopenia positively correlate with depression and anxiety [16] and increased levels of proinflammatory cytokines such as Interleukin 4/6 and tumor necrosis factor (TNF)-alpha, and platelet brain-derived neurotrophic factors (BDNF) account for the presence of depressive and anxiety symptoms among adult patients with DF [16].

Depression and anxiety have been investigated in children with fatigue syndrome, fibromyalgia, migraine/tension headache [19], chronic abdominal pain [20], juvenile idiopathic arthritis [21], cancer [22], and human immunodeficiency virus (HIV) [23], yet information among pediatric patients with DF remains inadequate. One prospective study provides information on neurologic manifestations of DF in children. Pancharoen and Thisyakorn [24] reported that 80 of 1493 (5.4\%) Thai in-patient children (3 months to 14 years old), who had serologically confirmed DF diagnosis, exhibited seizures and encephalopathy-like depressed sensorium and mental confusion during the febrile (acute) stage of DF based on recorded medical charts. However, studies that prospectively use a self-report screening tool to detect depressive and anxiety symptoms [25], which has a high acceptance and response rate $(99 \%)$ and a low refusal rate (1\%) among in- and out-patients [26], are lacking. To date, the study done by Mushtaq and Zahir [27] is the only known study, to our knowledge, that has used a self-report screening tool to measure depression, anxiety, and stress among pediatric patients with DF and investigated its relationship with self-efficacy. The study used the Depression Anxiety and Stress Scale (DASS) to measure depression, anxiety, and stress and the General Self-Efficacy Scale (GSES) to measure self-efficacy among the participants [27]. They found out that self-efficacy has a negative correlation with depression, anxiety, and stress; thus, developing self-efficacy among the patients is deemed necessary [27]. Although this study adds to the emerging topics on the presence of depressive and anxiety symptoms among pediatric patients with DF, there is still a pressing need to conduct more studies to measure the impact of DF infection on the mental health of pediatric patients.

Therefore, this study aimed to estimate the prevalence of depressive and anxiety symptoms among pediatric in-patients with DF and compare it with that among healthy school-based controls. We also sought to explore the predictors of these symptoms and to identify other self/parent-reported psychiatric manifestations that occur during the infection. We hypothesized that the prevalence of depressive or anxiety symptoms among pediatric patients with DF would be higher than that among controls, and predictors would include pain-related DF symptoms including headache, myalgia, arthralgia, retro-/peri-orbital pain, and abdominal pain suggesting a causal link between depressive, anxiety, and other psychiatric symptoms and DF infection. 


\section{Materials and Methods}

\subsection{Study and Sampling Design}

This case-control study involved pediatric patients (cases) admitted at three public tertiary (>100 beds) hospitals in Metro Manila, Philippines, from July to November 2017, during the high transmission of DF cases. Metro Manila was chosen due to an increase in the number of DF cases (15.5\% increase compared with previous year [28]) from 1 January to 6 May (morbidity week, 1-18), which was one of the highest rates in the country in 2017 [29]. Simultaneously, healthy grade 3 to 12 students, whose ages were similar with the cases, 8 to 17 years old, were also recruited to serve as controls. Since some of the patients with DF could not answer the test because of sickness, we asked their parents to answer the parent version of the screening tool. Thus, we also recruited parents of children whose age and grade level matched those of the patients with DF, as controls. We used the 1:1 ratio (one case patient/one control) with an assumed odds ratio of $\geq 2$, power (1- $\beta$ ) of $0.80,0.05$ significance level, $\mathrm{Z} \alpha=1.96$ [30], however, we were able to recruit a large number of controls. We failed to match them with the cases to control the confounding effects of age, gender, and grade level because availability of controls with matching criteria with the cases was limited during collection. While we also acknowledge the importance of obtaining controls in the same hospitals as the cases, we opted to sample controls in schools, who, like the cases, were students. We assumed that recruiting students as controls would increase our chance to sample healthy (no DF (like the cases) or any psychiatric and/or medical conditions) controls to investigate the true association between depressive and anxiety symptoms and DF infection.

\subsection{Participant Inclusion and Exclusion Criteria}

Participants were selected based on the pre-determined inclusion and exclusion criteria, availability, willingness to communicate their experiences and participate in the study [31-33]. A semi-structured interview was conducted among pediatric in-patients with serologically (laboratory) confirmed or clinically diagnosed DF and healthy school-based controls with no current or existing signs and clinical symptoms or diagnosis of DF. Recruitment of the patients and controls was also based on age (age 8-17 years) and grade level (grades 3 to 12) criteria of the Revised Child Anxiety and Depression Scale (RCADS-25), a screening tool for depressive and anxiety symptoms. Eligible participants had no history and/or existing diagnosis of psychiatric and/or medical conditions for which they received medical advice or treatment prior to the interview. Patients with life-threatening comorbidities and controls who were not able to comply with consent procedures were excluded.

\subsection{Ethical Considerations and Data Collection Procedures}

Our study was approved by the Research Ethics and Review Unit of San Lazaro Hospital, Research Ethics and Technical Committee of Pasay City General Hospital and Planning, Development, Education, and Research office of Quezon City General Hospital (ethics approval numbers: RERU-SLH 2017-016 E and PGH-RETC-01-0-091417001DENGUE). It complied with the ethics guidelines of the Declaration of Helsinki [34], International Council for Harmonization-Good Clinical Practice (ICH-GCP) guidelines [35], and National Ethical Guidelines for Health Research [36]. We also followed the reporting guidelines of case-control studies required by the STrengthening the Reporting of OBservational Studies in Epidemiology (STROBE) statement checklist in writing this manuscript (File S1).

All the participants (especially the patients, and their parents, legally authorized representatives (LARs) or caregivers) gave their consent before participating in this study. They were asked to read and sign an informed consent form (and assent form for children below 18 years old) in Filipino and were informed that participation in the study was voluntary and they may stop their participation at any time. Interviews were rescheduled for patients who could not participate due to sickness and severity of symptoms (e.g., intensive care unit confinement for severe dengue patients). In some cases, a parent, 
LAR or caregiver was asked to complete the forms and the RCADS-25-parent version for their children. Recruitment and interviews of patients were done by a primary investigator who underwent ICH-GCP guidelines training and with supervision from co-investigators (e.g., physicians, nurses) at each hospital. A psychologist and a guidance counselor recruited and interviewed the controls. A semi-structured interview (consistent pre-determined instructions, questions, and standardized screening tool) was done among all the participants to keep the data free from inconsistencies, incomplete responses, and biases. All forms and tests with confidential information of the participants were coded. Participants were informed about their scores on the tests, and a consent for further psychiatric assessment was solicited from those whose scores suggested a need for clinical intervention during follow-up and those who reported other psychiatric manifestations during the onset of the infection.

\subsection{Forms and Measures}

\subsubsection{Explanatory Variables}

Socio-demographic profile, clinical parameters and symptoms: Socio-demographic profile included age, civil status, gender, educational attainment, occupation, family's monthly income. and living arrangements. For age, we adjusted the age-disease association data (simple clustering method: k-means) which closely matched the accepted Medical Subject Heading (MeSH) ranges, into three age groups: 8-11, 12-14, and 15-17 based on the age criteria of RCADS-25 [37]. Income of the participants was identified by the help of their parents, guardian or LAR using the clusters from the indicative range of monthly family incomes (for a family of 5) in 2015 and 2017 [38]. However, we decided to have two clusters (above and below 10,000 pesos) as most of the patients had income below 10,000 pesos.

We also collected clinical information from the patients that included admitting diagnosis information, self and family history of DF, serologic test results (non-structural protein 1 antigen (NS1Ag) and blot test immunoglobin G antibody (IgG) and immunoglobin M antibody (IgM)) and laboratory data (i.e., complete blood count (CBC) with platelet count). The inclusion of family DF history was to investigate whether a previous diagnosis or history of DF in a family is associated with increased depressive and anxiety symptoms scores among the patients with DF. Clinical DF diagnosis was made under the following circumstances in three categories: probable (lived or traveled to endemic areas, has fever, and two DF symptoms); dengue hemorrhagic fever (DHF) with or without warning signs (abdominal pain, vomiting, mucosal bleeding, lethargy, liver enlargement $(>2 \mathrm{~cm})$, decreased platelet count or thrombocytopenia); and severe dengue (severe plasma leakage, hemorrhage, and organ impairment) [1]. These were used to identify the patient's current dengue infection phase (acute, febrile-critical, and recovery phase). Acute phase is the onset of high-grade fever and other warning signs (e.g., headache, myalgia, arthralgia, nausea and vomiting, mucosal bleeding, and thrombocytopenia) usually lasting for a week. Some patients may develop rashes, signaling the beginning of the recovery phase [1]. During this phase, well-being improves, some warning signs tend to abate, and platelet count typically starts to rise [1]. Clinical symptoms or warning signs were also queried.

\subsubsection{Response Variables}

The Revised Child Anxiety and Depression Scale (RCADS) is an assessment tool for screening depressive and anxiety symptoms in children and adolescents [39]. We used the RCADS-25 (25 items), the shorter version of RCADS-47 developed by Chorpita et al. [39], with child and parent versions [40]. The child version was administered to pediatric patients and controls, whereas the parent version was administered to parents of pediatric patients who could not complete the child version due to sickness and other comorbidities. RCADS-25 has two scales: depression (10 items) and anxiety (15 items); items were rated on a 4-point Likert-scale from 0 ("never") to 3 ("always") and were scored and interpreted using a "t-score" [40]. T-scores are transformed raw scores used to obtain a normal distribution with a 
maximum score of 80 . A $t$-score of 65 means borderline and a $t$-score of 70 means clinical threshold [40]. The $t$-scores were adjusted for gender (girl and boy) and grade level (grade 3 to 12); the child version has different $t$-scores from the parent version [40]. Both depression and anxiety scales have good internal consistency (Cronbach's alpha) of $\alpha=0.78$ and $\alpha=0.88$ in clinical and general or school-based populations [37-41]. This tool has been reported to be a cross-culturally reliable measure of depressive and anxiety symptoms for children and adolescents [42].

Both RCADS-25 child and parent forms were translated to Filipino (Tagalog) by independent bilingual translators and was then face, content, and construct validated by experts [43]. Then it was pilot tested among selected clinical and school-based samples. When a consensus was reached, it was translated back to English by bilingual translators. We calculated the internal consistency (Cronbach's alpha) of the RCADS-25 child and parent forms in Filipino, and results evidenced an acceptable internal consistency which ranged from $\alpha=0.70$ to $\alpha=0.80$ in clinical samples and $\alpha=0.73$ to $\alpha=0.83$ in school-based samples, but were not included in the final analysis.

RCADS-25 was used to screen the presence of depressive or anxiety disorder symptoms and not to diagnose disorders associated with the mentioned symptoms. Thus, we recommended further psychiatric assessment among patients whose scores suggested the presence of borderline or clinical levels of depressive and anxiety symptoms.

Self/parent-reported psychiatric manifestations: Patients and their parents/guardians were also asked to report other psychiatric manifestations that they observed during the onset of the disease and hospitalization through a structured interview based on the diagnostic criteria of depressive and anxiety disorders of the Diagnostic and Statistical Manual of Mental Disorders 5th Edition (DSM-V) [44]. Similar to the results of the RCADS-25, patients who reported the presence of psychiatric symptoms were also recommended for further psychiatric assessment.

\subsection{Statistical and Data Analysis}

Statistical analyses were conducted using the Statistical Package for Social Sciences version 25 (IBM Corp., Armonk, NY, USA). The Chi-squared test was used to test the significant differences between the groups in terms of their socio-demographic profile and in the prevalence (\%) of pediatric patients and controls with borderline or clinical depressive and anxiety symptoms. Odds ratio effect sizes were also computed to measure the differences in the proportion of those with depressive and anxiety symptoms among pediatric and controls. An independent $t$-test (2-tailed) was also conducted to test the significant differences in the mean depression and anxiety scores ( $t$-scores) between the two groups. We also reported the effect sizes of the mean differences between the two groups in depressive and anxiety symptoms by calculating Cohen's $d$, Glass' delta, and Hedges' $g$ effect size estimations. Multiple linear regression was done by inputting all variables (dummy variables (i.e., 0 or 1) for categorical variables) in the model using a stepwise method in forward selection to identify significant $(p<0.05)$ predictors of depressive and anxiety symptoms. Patients' reported psychiatric manifestations were translated into English by an independent bilingual translator and were analyzed using content analysis, a method that can identify patterns across qualitative data (words or phrases) that can be counted (frequency) for quantitative analyses [45-47].

\section{Results}

\subsection{Socio-Demographic Profile, Clinical Parameters, and Symptoms}

Initially, 625 participants (pediatric patients $n=321$; controls $n=304$ ) were recruited in the study, but only 485 (pediatric patients $n=225$; controls $n=260$ ) were found eligible, complied to the informed consent procedures, and participated in this study. Among the 225 data collected from the patients with DF, 155 (68.9\%) were from pediatric patients with DF and 70 (31.1\%) were from parents of other patients with DF who could not answer the screening tool. Similarly, the 260 data collected among 
controls were from $220(84.6 \%)$ students and 40 (15.4\%) parents of children who had the same age and grade level as the patients with DF. The profile of the participants is shown in Table 1.

Table 1. Socio-demographics, clinical parameters, and clinical symptoms of pediatric patients with dengue fever (DF) and controls.

\begin{tabular}{|c|c|c|c|c|}
\hline \multirow{2}{*}{\multicolumn{2}{|c|}{ Socio-Demographic Profile }} & \multirow{2}{*}{$\begin{array}{c}\text { Patients } \\
n=225\end{array}$} & \multirow{2}{*}{$\begin{array}{c}\text { Controls } \\
n=260\end{array}$} & \multirow{2}{*}{$\begin{array}{c}X^{2} \\
p \text {-Value }\end{array}$} \\
\hline & & & & \\
\hline \multirow{2}{*}{ Gender } & Male & $120(53.3)$ & $133(51.2)$ & 0.65 \\
\hline & Female & 105 (46.7) & $127(48.8)$ & \\
\hline \multirow{3}{*}{ Age } & $8-11$ & $71(31.6)$ & $132(50.8)$ & $<0.001$ \\
\hline & $12-14$ & $67(29.8)$ & $61(23.5)$ & \\
\hline & $15-17$ & 87 (38.7) & $67(25.8)$ & \\
\hline \multirow{3}{*}{ Education } & Grade School & $78(35.6)$ & $132(50.8)$ & 0.004 \\
\hline & Junior HS & $106(48.4)$ & $94(36.2)$ & \\
\hline & Senior HS & $35(16.0)$ & $34(13.1)$ & \\
\hline \multirow{2}{*}{ Income $(\mathbb{P})$} & $\leq 10,000 \mathrm{PHP}$ & $171(83.4)$ & $21(9.0)$ & $<0.001$ \\
\hline & $\geq 11,000 \mathrm{PHP}$ & $34(16.6)$ & $213(91.0)$ & \\
\hline \multirow{3}{*}{ Household size } & $\leq 5$ members & $110(53.12)$ & $209(88.6)$ & $<0.001$ \\
\hline & $\geq 6$ members & $97(46.9)$ & $27(11.4)$ & \\
\hline & Clinical Parameters & & & \\
\hline \multirow{4}{*}{ Medical diagnosis } & Clinical & $24(10.7)$ & & \\
\hline & Probable & $23(10.2)$ & & \\
\hline & DHF w/ws & $172(76.4)$ & & \\
\hline & Severe dengue & $6(2.67)$ & & \\
\hline \multirow{2}{*}{ Days in the hospital } & $\leq 2$ days & $150(66.7)$ & & \\
\hline & $\geq 3$ days & $46(20.4)$ & & \\
\hline \multirow{2}{*}{ DF history } & Had DF & $11(4.89)$ & & \\
\hline & First-time & $185(82.2)$ & & \\
\hline \multirow{2}{*}{ Family DF history } & None & $135(60.0)$ & & \\
\hline & $\geq 1$ member/s had DF & $59(26.2)$ & & \\
\hline \multirow{2}{*}{ Dengue phase } & Acute & $179(79.6)$ & & \\
\hline & Recovery & $46(20.4)$ & & \\
\hline \multirow{6}{*}{ Dengue tests } & (-) NS1Ag & $59(26.2)$ & & \\
\hline & (+) NS1Ag & $39(17.3)$ & & \\
\hline & $(-) \operatorname{IgG}$ & $21(9.33)$ & & \\
\hline & $(+) \operatorname{IgG}$ & $39(17.3)$ & & \\
\hline & (-) IgM & $48(21.3)$ & & \\
\hline & $(+) \operatorname{IgM}$ & $12(5.33)$ & & \\
\hline \multicolumn{5}{|c|}{ Clinical Symptoms } \\
\hline Headache & Symptomatic & $35(15.6)$ & & \\
\hline Fever & Symptomatic & $38(16.9)$ & & \\
\hline Nausea and vomiting & Symptomatic & $55(24.4)$ & & \\
\hline Retro-/peri-orbital pain & Symptomatic & $16(7.11)$ & & \\
\hline Myalgias \& arthralgias & Symptomatic & $48(21.3)$ & & \\
\hline Abdominal pain & Symptomatic & $87(38.7)$ & & \\
\hline Petechiae (rash) & Symptomatic & $96(42.7)$ & & \\
\hline Thrombocytopenia & $\leq 9900 / \mathrm{mm}^{3}$ & $143(63.5)$ & & \\
\hline
\end{tabular}

DF-dengue fever; HS—high school; P-Philippine peso (52.16 USD = 1 P); Acute—febrile to critical phase; ws—warning signs; DHF—dengue hemorrhagic fever; $(+)$ - positive; (-)—negative; NS1 Ag—non-structural protein 1 antigen; IgG—immunoglobin $\mathrm{G}$ antibody; IgM—immunoglobin M antibody. 
The two groups had significantly different proportions and distributions in terms of their age, education, income, and households. In terms of gender, the two groups were significantly the same, where both had nearly the same distribution (50\%) of each gender. Pediatric patients had a mean age $(\mathrm{M})$ of 10.96 and a standard deviation $( \pm)$ of 2.95 years, 53\% were males, the majority had DHF with warning signs (76.4\%) and were in the acute (febrile-critical) phase of DF (79.6\%) of the infection. Thrombocytopenia (low platelet counts) and petechiae (rashes) were the most commonly reported symptoms among the patients. The controls, male $(n=133)$ and female $(n=127)$, had a mean age of 12 $( \pm 2.8)$ years.

\subsection{Prevalence and Mean Score Differences of Depressive and Anxiety Symptoms}

More pediatric patients with DF (13.3\%) had borderline or clinical depressive symptoms than controls $(3.5 \%)$. Similarly, a significant proportion $(34.2 \%)$ of pediatric patients with DF compared with controls $(n=42 ; 16.2 \%)$ had borderline or clinical anxiety symptoms. Chi-squared analyses also revealed that pediatric patients with DF had a significantly $(p \leq 0.001)$ higher prevalence of depressive and anxiety symptoms than the controls, as shown in Table 2 . This represents the fact that based on the odds ratio, pediatric patients were 4.3 times more likely to have depressive symptoms and 2.7 times more likely to have anxiety symptoms than controls. Moreover, when we compared the mean scores of the participants, pediatric patients had significantly $(p \leq 0.001)$ higher mean depressive and anxiety mean scores than controls (also shown in Table 2). The significant effects in the differences between the mean scores also represented a fairly substantial medium effect sized estimations in depression $(\mathrm{r}=0.30-0.32)$ and anxiety $(\mathrm{r}=0.30-0.34)$ between the two groups based on Cohen's $d$, Gates' delta, and Hedges' $g$ effect size estimations.

Table 2. Prevalence and mean score differences of depressive and anxiety symptoms between pediatric patients with DF and controls.

\begin{tabular}{ccccccc}
\hline & \multicolumn{3}{c}{ Prevalence } & \multicolumn{3}{c}{ Mean Score Difference } \\
\cline { 2 - 7 } Symptoms & $\begin{array}{c}\text { Patients } \\
(\boldsymbol{n}=\mathbf{2 2 5})\end{array}$ & $\begin{array}{c}\text { Controls } \\
(\boldsymbol{n}=\mathbf{2 6 0 )}\end{array}$ & $\boldsymbol{X}^{\mathbf{2}}$ & $\begin{array}{c}\text { Patients } \\
(\boldsymbol{n}=\mathbf{2 2 5})\end{array}$ & $\begin{array}{c}\text { Controls } \\
(\boldsymbol{n}=\mathbf{2 6 0 )}\end{array}$ & $\begin{array}{c}\boldsymbol{t} \text {-Test } \\
(\mathbf{2 - T a i l e d )})\end{array}$ \\
\cline { 2 - 7 } & $\boldsymbol{n ( \% )}$ & $\boldsymbol{n ( \% )}$ & $\boldsymbol{p}$-Value & Mean (SD) & Mean (SD) & $\boldsymbol{p}$-Value \\
\hline Depressive symptoms & $30(13.3)$ & $9(3.5)$ & $<0.001$ & $52.3(9.87)$ & $49.3(8.64)$ & $<0.001$ \\
Anxiety symptoms & $77(34.2)$ & $42(16.2)$ & $<0.001$ & $59.3(11.5$ & $55.8(9.34)$ & $<0.001$ \\
\hline
\end{tabular}

\subsection{Predictors of Depressive and Anxiety Symptoms}

The multiple linear regression analysis (Table 3$)$ showed significant $(p<0.001)$ regression models in depressive and anxiety symptoms. Although the coefficients $\left(R^{2}\right)$ were low $(<1)$, significant predictors like the presence of myalgias and arthralgias and a family history of DF were found to increase the depressive symptoms score, whereas $\leq 2$ days of hospitalization and age (older) both increased anxiety symptom scores among pediatric patients with DF.

Table 3. Predictors of depressive and anxiety symptoms among pediatric patients with DF.

\begin{tabular}{|c|c|c|c|c|c|}
\hline Outcome Variables & Predictors & $R^{2}$ & $\beta$ & $\begin{array}{l}\text { Predictor } \\
p \text {-Value }\end{array}$ & $\begin{array}{c}\text { Model } \\
p \text {-Value }\end{array}$ \\
\hline \multirow{2}{*}{ Depressive symptoms } & Myalgias and arthralgias & 0.07 & 4.87 & 0.002 & $<0.001$ \\
\hline & Family history of DF & & 3.19 & 0.028 & \\
\hline \multirow{2}{*}{ Anxiety symptoms } & Age & 0.15 & 1.26 & $<0.001$ & $<0.001$ \\
\hline & Days in the hospital ( $\leq 2$ days) & & 1.26 & 0.005 & \\
\hline
\end{tabular}




\subsection{Self/Parent-Reported Psychiatric Manifestations}

Table 4 shows the results of content analysis on the reported psychiatric manifestations during the onset of infection. Our quantitative analysis shows that $60(26.7 \%)$ pediatric patients with DF had irritable mood or irritability, agitation, visual hallucinations, and aggressiveness during the onset of dengue infection. However, the reports of these manifestations were not sufficiently intense and not clinically assessed by a psychiatrist (patients' unwillingness to be referred) to qualify for an anxiety disorder or depressive disorder due to the span (less than six months) of time these symptoms were present among the patients.

Table 4. Self/parent-reported psychiatric manifestations among pediatric patients with DF using content analysis and quantitative analysis.

\begin{tabular}{|c|c|c|c|}
\hline Manifestations (In Filipino) * & English Translation/Meaning & $\begin{array}{l}\text { Patterns } \\
(\text { DSM-V) }\end{array}$ & $\begin{array}{l}\text { Pediatric Patients } \\
\quad(n=60)\end{array}$ \\
\hline $\begin{array}{l}\text { Mainit ang ulo } \\
\text { Mainitin ang ulo }\end{array}$ & $\begin{array}{l}\text { Irritable mood } \\
\text { Irritable }\end{array}$ & Irritable mood & $24(40.0)$ \\
\hline $\begin{array}{c}\text { Irritable } \\
\text { Naiirita } \\
\text { Bugnutin }\end{array}$ & $\begin{array}{c}\text { Irritable } \\
\text { Irritable } \\
\text { Quick-tempered }\end{array}$ & Irritability & $12(20.0)$ \\
\hline Worry & Worry & & \\
\hline Kinakabahan o natatakot & $\begin{array}{l}\text { Nervous/fear that something awful } \\
\text { might happen }\end{array}$ & Worry & $2(3.3)$ \\
\hline $\begin{array}{l}\text { Nag-Hallucinate noong nilalagnat } \\
\text { Isip-bata } \\
\text { Hindi kami kilala; iba ang nakikita } \\
\text { niyang mukha noong nilalagnat }\end{array}$ & $\begin{array}{l}\text { Hallucination } \\
\text { Childish } \\
\text { Visual hallucination }\end{array}$ & Hallucination & $4(6.7)$ \\
\hline Madalis magalit & Easily-angered/agitated & & \\
\hline Pikon & Easily angered by jokes or jests, touchy & Agitation & $9(15.0)$ \\
\hline Masungit & Ill-tempered, short-tempered/agitated & & \\
\hline $\begin{array}{l}\text { Aggressive } \\
\text { Sumisigaw }\end{array}$ & $\begin{array}{l}\text { Aggressive } \\
\text { Shouting }\end{array}$ & Aggression & $4(6.7)$ \\
\hline $\begin{array}{l}\text { Hindi Nagsasalita } \\
\text { Tahimik }\end{array}$ & $\begin{array}{l}\text { Does not talk } \\
\text { Quiet }\end{array}$ & Quiet & $2(3.3)$ \\
\hline Tinatamad & Laziness & & \\
\hline Matamlay & $\begin{array}{l}\text { Listless: seeming too tired to care about } \\
\text { anything, not interested in things, not } \\
\text { caring to be active }\end{array}$ & Fatigue & $2(3.3)$ \\
\hline Nanghihina & Feeling weak & & \\
\hline Mahirap kausap & Hard to talk with & Hard to talk with & $1(1.67)$ \\
\hline
\end{tabular}

* Responses in Filipino (Tagalog) language were analyzed and translated to English by an independent bilingual translator; ${ }^{\text {a }}$ based on the Diagnostic and Statistical Manual of Mental Disorders 5th Edition (DSM-V) diagnostic criteria for depressive and anxiety disorders.

\section{Discussion}

Results show that the prevalence of depressive (13.3\%) and anxiety (34.2\%) symptoms among pediatric patients with DF was significantly $(p \leq 0.001)$ higher than that among controls $(3.5 \%$ and $16.2 \%$, respectively). Similarly, analysis of mean scores also showed that pediatric patients had significantly $(p \leq 0.001)$ higher depressive and anxiety mean scores than controls. The regression model identified that the presence of myalgias and arthralgias, family history of $\mathrm{DF}, \leq 2$ days of hospitalization, and age (older) were significant $(p \leq 0.001)$ predictors of increased depressive and anxiety symptoms among pediatric patients with DF. Additionally, $26.7 \%$ of pediatric patients with DF also reported psychiatric manifestations like irritability, agitation, visual hallucinations, and aggressiveness during the onset of the infection. 
To our knowledge, this study is one of the very first reports to measure the prevalence of depressive and anxiety symptoms among patients with DF; more so, among pediatric patients with DF compared it to controls with the use of a standardized self-report screening tool. The study also provided an initial investigation on the predictors of anxiety and depressive symptoms among pediatric patients with DF by including clinical data (e.g., DF history, serologic test results, DF symptoms). This study also extends previous quantitative and qualitative (case studies) studies by using a standardized screening tool and structured interview in collecting information on the presence of psychiatric manifestations during the onset of infection. Thus, the combination of these quantitative and qualitative techniques was also considered as one of the strengths of this study.

The difference between the prevalence of depressive and anxiety symptoms between pediatric patients and controls may have been brought about by the presence of pain related to myalgia and arthralgia which was one of the predictors of increased depressive symptom scores. The presence of these symptoms has been reported to be the result of inflammatory cytokines, such as Interleukin-1 beta (IL-1 $\beta$ ), Interleukin-2 (IL-2), and Interleukin-6 (IL-6) [48]. These cytokines were found to be of significantly higher levels among children and adolescents with major depressive disorder (MDD) compared with healthy controls [49-52]. Thus, we propose that the presence of these cytokines, which were absent among controls, may explain the possible presence and increased levels of depressive symptoms among pediatric patients during DF infection.

Predictors like $\leq 2$ days of hospitalization and family history of DF, may also explain the increased depressive mood and anxiety symptoms among pediatric patients compared to that of controls. High depressive and anxiety symptoms during the $\leq 2$ days of hospitalization would have been aggravated by the pediatric patients' fear of medical settings and receiving medical care as common symptoms of anxiety [53]. Children usually report medical procedures, such as drawing of blood, as traumatic and seeing medical professionals as traumatic as well [54]. Further, family history of DF also tended to increase depressive symptoms among pediatric patients with DF. An indicator of anxiety disorders in children is worrying about multiple issues like future events [55], for instance, contracting DF. This can be linked to a painful past experience, such as a family member diagnosed with, and hospitalized due to, DF. Observing the severity and seriousness of symptoms, the level of associated pain may have affected patients' perception of the disease and thus their response may have presented as depressive symptoms. Unlike controls, pediatric patients with DF were anxious of hospital conditions like limited food options, limited physical activities, limited time playing with friends, and being absent in school [56,57].

Opposite to the results of our previous study which found that as the age of pediatric patients with DF increased, their attitude towards DF decreased [58], this present study found that as their age increased, their anxiety also increased. Thus, their knowledge about their disease, rather than their attitude towards it, may explain this finding. It has been reported that children and adolescents with chronic illnesses have limited knowledge of their conditions and perceive their diseases differently from a much older population [59,60]. Thus, older children who have more of an ability to correctly understand the meaning of their disease and its severity, had higher anxiety symptoms than the younger ones.

Our study also extends previous studies which reported adult patients with DF had auditory and visual hallucinations, agitation and delusional fears, irritable affect or behavior, persecutory delusions, and psychotic episodes during DF infection [7,12]. Our results confirm that pediatric patients with DF also exhibit psychiatric manifestations during DF infection. Although these manifestations were not qualified to be considered as depressive and anxiety disorder symptoms due to the duration of their presence, it still confirms that these symptoms also impact children with DF. We found out that $26.7 \%$ of pediatric patients with DF reported irritable mood/irritability, visual hallucination, agitation, and aggressiveness. Children are more likely to be irritable, agitated and report possible delusions or hallucinations which are symptoms of $\operatorname{MDD}[53,61]$, than older patients. Irritability which is an overlapping symptom among children and adolescents [55], is also a diagnostic criterion for anxiety 
disorder, for MDD and for disruptive mood dysregulation disorder of the new DSM-V and oppositional defiant disorder (ODD) of the International Classification of Disorders (ICD-11) among children [62]. Further, hallucinations are key features of psychotic conditions and acute neurological states, such as encephalitis, and are often presented with delirium and delusions which are more prevalent in children than adults [63]. Since these results were not confirmed by a psychiatric assessment, studies that include clinical assessment by a psychiatrist and evaluation through imaging techniques may help shed light on whether these symptoms are associated with DF infection virus or not.

The low consent rate $(<1 \%)$ for referral to further psychiatric assessment to assess the false positive and negative responses of the patients in the screening tool and reported psychiatric symptoms, has highlighted how patients view mental health disorders. This may be affected by cultural orientation and perception of depressive and anxiety symptoms and treatment-seeking response among patients with DF in this study. In the Philippines for example, as a collectivist-oriented culture [64], with greater social support and where family and wider society are more highly considered than one's own self, a lower tendency to develop depressive disorder symptoms can be expected [65]. Moreover, many cultures view mood disorders as a social and moral problem associated with stigma and loss of reputation, not as mental health problems [66]. These conditions are perceived as a moral or character development that requires self-mastery and endurance and help or treatment with medication is seen as unnecessary [67].

We also identified a number of limitations in our methods: failure to match cases with controls, income and hospital setting, time of collection and lack of further psychiatric assessment by a psychiatrist. First, we failed to match pediatric patients with DF and controls at least by age which decreased the ability of our study to draw generalizable conclusions from the findings. As we mentioned, matching cases and controls was difficult due to the limited number of eligible controls. Second, the inclusion of public tertiary hospitals limited the study findings to low-income families, thus, future studies may include patients admitted to private hospitals to see whether income and hospital setting are confounding the relationship between depressive and anxiety symptoms and DF infection. Third, this study is limited only to DF cases during the peak transmission or rainy seasons from July to November. Thus, the results that patients with DF had high depressive and anxiety symptoms during this time may not apply to other periods where there is low transmission of DF. Future studies may rely in comparing patients interviewed during the high transmission season and patients interviewed during low transmission season in order to investigate whether results collected may be generalizable in any period of time and not due to the panic and alarm brought by a large number of DF cases. The fourth and the most important, was the lack of further psychiatric assessment by a psychiatrist to confirm the scores (false positive responses) in RCADS-25 and the reported psychiatric manifestations. Other than the scores in RCADS-25, we had no other means to encourage them to seek further psychiatric assessment.

\section{Conclusions}

Our study highlights that there was a high prevalence of depressive and anxiety symptoms among pediatric patients with DF compared with controls, due to social and clinical factors which might be associated with DF infection. We also learned that pediatric patients with DF also exhibit psychiatric manifestations such as irritable mood/irritability, visual hallucination, agitation, and aggressiveness like adult patients with DF which has been reported in previous studies. Thus, it is important to screen patients with DF for these psychiatric symptoms, and if necessary, healthcare professionals must refer and encourage them to seek help to avoid long-term post-DF chronic psychiatric complications in the future. However, information on whether these symptoms are present only during the infection and may disappear on their own or may still persist after the infection, is unknown. Thus, longitudinal post-DF recovery studies would provide information on the possibilities that these symptoms may or may not develop to subsequent chronic psychiatric conditions in the future. Most importantly, this study provides benchmark information on the possible causal or direct link between depressive and 
anxiety symptoms and DF infection among pediatric patients with DF, yet, there is insufficient evidence to draw conclusions. Thus, the potential trauma of hospitalization and not directly DF infection, may have caused the increased depressive and anxiety symptoms among the pediatric patients with DF. Therefore, future studies must distinguish between children's adverse reactions to hospitalization and psychiatric symptoms due to DF. While RCADS- 25 is widely used and psychometrically salient, the lack of further psychiatric assessment among patients with borderline or clinical depressive and anxiety symptoms and who reported the presence of other psychiatric symptoms, hindered us to conclude whether these symptoms were directly due to DF infection or not. More so, determining whether the findings may only be specific to pediatric patients with DF infection or may be extended to children with other serious infectious diseases in general, also remains unknown and needs further studies.

Supplementary Materials: The following are available online at http://www.mdpi.com/1660-4601/17/1/99/s1. Supplementary File S1: STROBE statement.

Author Contributions: V.R.D.M.H. designed the study, wrote the protocol, conducted the interviews, analyzed the data, and wrote the manuscript. F.S.d.G., G.D.S., and A.B.F.C. were assigned as co-investigators in each hospital site and supervised patient recruitment and data gathering. A.C.V.T. and C.M.A.-d.R. provided guidance and comments on the initial drafts of the study protocol including literature review, sampling, data gathering methods, and ethical considerations. Author R.A.R. supervised the interviews, testing and scoring procedures for the controls. Author M.M.T. worked with V.R.D.M.H. on the submission to approve the study protocol in the hospitals and was involved in the overall data gathering procedures. Author K.W. supervised the data gathering and provided guidance and comments on the analysis and the initial drafts of this manuscript. All authors have read and agreed to the published version of the manuscript.

Funding: This study was supported by the Japan Society for the Promotion of Science (JSPS) Grant-in-Aid for Scientific Research (17H01624, 19H01144), JSPS Core-to-Core Program B. Asia-Africa Science Platforms, and Endowed Chair Program of the Sumitomo Electric Industries Group Corporate Social Responsibility Foundation, which had no role in the design, data collection, statistical analysis, and writing of this manuscript.

Acknowledgments: The authors would like to thank Jocelyn C. Ortiz, Jose M. Ocampo Jr., and Cecilia M. Resureccion for their assistance in the validation of the Filipino version of the RCADS-25. We would also like to thank Jazteene Dale M. Villarama, Joenna Mari P. Cabarloc, and Jayne Nicholei C. Borricano for their assistance during data gathering. Most importantly, we are grateful to all the patients and controls who participated in this study.

Conflicts of Interest: The authors declare that they have no competing interests.

\section{References}

1. World Health Organization. Dengue: Guidelines for Diagnosis, Treatment, Prevention and Control. New Edition 2009. Available online: http://www.who.int/tdr/publications/documents/dengue-diagnosis.pdf (accessed on 3 May 2017).

2. World Health Organization: Dengue and Dengue Haemorrhagic Fever. Factsheet. 2008. Available online: http://www.who.int/mediacentre/factsheets/fs117/en (accessed on 12 May 2017).

3. Brady, O.J.; Gething, P.W.; Bhatt, S.; Messina, J.P.; Brownstein, J.S.; Hoen, A.G.; Hay, S.I. Refining the global spatial limits of dengue virus transmission by evidence-based consensus. PLoS Negl. Trop. Dis. 2012, 6, e1760. [CrossRef] [PubMed]

4. Li, G.H.; Ning, Z.J.; Liu, Y.M.; Li, X.H. Neurological Manifestations of Dengue Infection. Front. Cell Infect. Microbiol. 2017, 7, 449. [CrossRef] [PubMed]

5. Ramos, C.; Sanchez, G.; Pando, R.H.; Baquera, J.; Hernandez, D.; Mota, J.; LlausÁS, E. Dengue virus in the brain of a fatal case of hemorrhagic dengue fever. J. Neurovirol. 1998, 4, 465-468. [CrossRef] [PubMed]

6. Oehler, E.; Le Hénaff, O.; Ghawche, F. Neurological manifestations of dengue. Presse Med. 2012, 41, e547-e552. [CrossRef] [PubMed]

7. Blum, J.A.; Pfeifer, S.; Hatz, C.F. Psychiatric manifestations as the leading symptom in an expatriate with dengue fever. Infection 2010, 38, 341-343. [CrossRef]

8. Chavez, M.E.; Rojas, M.; Fortea, A. Post-dengue psychosis: Report of 4 cases. Eur. Neuropsychopharmacol. 2016, 2, 574-575. [CrossRef]

9. Jhanjee, A.; Bhatia, M.S.; Srivastava, S. Mania in dengue fever. Ind. Psychiatry J. 2011, 2, 56-57. 
10. Aggarwal, A.; Nimber, J.S. Dengue fever-associated catatonia. J. Neuropsychiatry Clin. Neurosci. 2015, 27, e66-e67. [CrossRef]

11. Tripathi, S.M.; Mishra, N. Late onset mania in dengue fever. Immunol. Infect. Dis. 2014, 2, 1-3.

12. Chaudhury, S.; Jagtap, B.; Ghopsh, D.K. Psychosis in dengue fever. Med. J. DY Patil Vidyapeeth 2017, 10, 202. [CrossRef]

13. Mhendekar, D.N.; Aggarwal, P.; Aggarwal, A. Classical mania associated with dengue infection. Ind. J. Med. Sci. 2006, 60, 115-116. [CrossRef] [PubMed]

14. Harder, J.; Sharma, S.; Gitlin, D. Secondary Mania as a Possible Neuropsychiatric Complication of Dengue Fever. Psychosomatics 2014, 55, 512-516. [CrossRef] [PubMed]

15. Gill, K.; Ahmad, W.; Irfan, M. A Clinical study to see the effects of dengue fever. Pak. J. Med. Health Sci. 2011, 5, 101-104.

16. Hashmi, A.M.; Butt, Z.; Idrees, Z.; Niazi, M.; Yousaf, Z.; Haider, S.F.; Bhatti, M.R. Anxiety and depression symptoms in patients with dengue fever and their correlation with symptom severity. Int. J. Psychiatry Med. 2012, 44, 199-210. [CrossRef] [PubMed]

17. Khan, M.A.; Ahmad, M.; Mir, S.; Iftikhar, F.; Fahad, M.; Khalid, M. Anxiety and depression in patients of dengue fever. Rawal Med. J. 2012, 37, 3.

18. Jhanjee, A.; Bhatia, M.S.; Srivastava, S.; Rathi, A. A Study of Psychiatric Symptomatology in Dengue Patients. Delhi Psychiatry J. 2013, 16, 21-23.

19. Pinquart, M.; Shen, Y.; Psych, C. Depressive Symptoms in Children and Adolescents with Chronic Physical Illness: An Updated Meta-Analysis. J. Pediatr. Psychol. 2011, 36, 375-384. [CrossRef]

20. Claar, R.L.; Baber, K.F.; Simons, L.E.; Logan, D.E.; Walker, L.S. Pain coping profiles in adolescents with chronic pain. Pain 2008, 140, 368-375. [CrossRef]

21. Mullick, M.S.; Nahar, J.S.; Haq, S.A. Psychiatric morbidity, stressors, impact, and burden in juvenile idiopathic arthritis. J. Health Popul. Nutr. 2005, 23, 142-149.

22. Schultz, K.A.; Ness, K.K.; Whitton, J.; Recklitis, C.; Zebrack, B.; Robison, L.L.; Mertens, A.C. Behavioral and social outcomes in adolescent survivors of childhood cancer: A report from the childhood cancer survivor study. J. Clin. Oncol. 2007, 25, 3649-3656. [CrossRef]

23. Wang, B.; Li, X.; Barnett, D.; Zhao, G.; Zhao, J.; Stanton, B. Risk and protective factors for depression symptoms among children affected by HIV/AIDS in rural China: A structural equation modeling analysis. Soc. Sci. Med. 2012, 74, 1435-1443. [CrossRef] [PubMed]

24. Pancharoen, C.; Thisyakorn, U. Neurological manifestations in dengue patients. Southeast Asian J. Trop. Med. Public Health 2001, 32, 341-345.

25. De Guzman, M.L.R. The validation study of the HADS among medically-ill. Acta Med. Philipp. 2013, 47, 53-62.

26. Salkovskis, P.; Storer, D.; Atha, C.; Warwick, H. Psychiatric morbidity in an accident and emergency department: Characteristics of patients at presentation and one-month follow-up. Br. J. Psychiatry 1990, 156, 483-487. [CrossRef] [PubMed]

27. Mushtaq, M.; Zahir, M. Depression, anxiety, stress and their effect upon the self-efficacy in dengue patients. J. Postgrad. Med. Inst. 2016, 30, 62-65.

28. Department of Health. Weekly Dengue Cases Report, Morbidity Week 28: July 10-16 July 2016. Epidemiology Bureau, Public Health Surveillance Division. 2016. Available online: https://www.doh.gov.ph/sites/default/ files/statistics/DENGUE\%20MW28.pdf (accessed on 5 May 2017).

29. Department of Health. Weekly Dengue Cases Report, Morbidity Week 18: January 1-6 May 2017. Epidemiology Bureau, Public Health Surveillance Division. 2017. Available online: https://www.doh. gov.ph/sites/default/files/statistics/2017_Dengue_MW1-MW18.pdf (accessed on 5 May 2018).

30. Charan, J.; Biswas, T. How to calculate sample size for different study designs in medical research? Ind. J. Psychol. Med. 2013, 35, 121-126. [CrossRef]

31. Etikan, I.; Musa, S.A.; Alkassim, R.S. Comparison of convenience sampling and purposive sampling. Am. J. Theor. Appl. Stat. 2016, 5, 1-4. [CrossRef]

32. Palinkas, L.A.; Horwitz, S.M.; Green, C.A.; Wisdom, J.P.; Duan, N.; Hoagwood, K. Purposeful Sampling for Qualitative Data Collection and Analysis in Mixed Method Implementation Research. Adm. Policy Ment. Health 2015, 42, 533-544. [CrossRef] 
33. Palys, T. Purposive sampling. In Sage Encyclopedia of Qualitative Research Methods; Given, L.M., Ed.; Sage: Los Angeles, CA, USA, 2008.

34. World Medical Association. World Medical Association Declaration of Helsinki Ethical Principles for Medical Research Involving Human Subjects. JAMA 2013, 310, 2191-2194. [CrossRef]

35. European Medicines Agency. ICH Topic E6 (R1) Guideline for Good Clinical Practice Step 5 Note for Guidance on Good Clinical Practice; CPMP/ICH/135/95: London, UK, 2002.

36. Philippine Health Research Ethics Board. National Ethical Guidelines for Health Research; PNHRS: Taguig City, Philippines, 2011.

37. Geifman, N.; Cohen, R.; Rubin, E. Redefining meaningful age groups in the context of disease. Age 2013, 6, 2357-2366. [CrossRef]

38. Albert, J.R.G.; Santos, A.G.F.; Vizmanos, J.F.V. Profile and Determinants of the Middle-Income Class in the Philippines; Philippine Institute for Development Studies: Quezon City, Philippines, 2018. Available online: https://pidswebs.pids.gov.ph/CDN/PUBLICATIONS/pidsdps1820.pdf (accessed on 25 October 2019).

39. Chorpita, B.F.; Yim, L.; Moffitt, C.; Umemoto, L.A.; Francis, S.E. Assessment of symptoms of DSM-IV anxiety and depression in children: A revised child anxiety and depression scale. Behav. Res. Ther. 2000, 38, 835-855. [CrossRef]

40. Ebesutani, C.; Reise, S.P.; Chorpita, B.F.; Ale, C.; Regan, J.; Young, J.; Weisz, J.R. The Revised Child Anxiety and Depression Scale-Short Version: Scale reduction via exploratory bifactor modelling of the broad anxiety factor. Psychol. Assess. 2012, 24, 833-845. [CrossRef] [PubMed]

41. Chorpita, B.F.; Moffitt, C.E.; Gray, J. Psychometric properties of the Revised Child Anxiety and Depression Scale in a clinical sample. Behav. Res. Ther. 2005, 43, 309-322. [CrossRef] [PubMed]

42. Piqueras, J.A.; Martin-Vivar, M.; Sandin, B.; San Luis, C.; Pineda, D. The Revised Child Anxiety and Depression Scale: A systematic review and reliability generalization meta-analysis. J. Affect. Disord. 2017, 218, 153-169. [CrossRef] [PubMed]

43. White, J.; Simon, M.K. Survey/Interview Validation Rubric for Expert Panel-VREP. 2014. Available online: http: //dissertationrecipes.com/wp-content/uploads/2011/04/Expert-Validation-v3.pdf (accessed on 23 May 2017).

44. American Psychiatric Association. Diagnostic and Statistical Manual of Mental Disorders, 5th ed.; American Psychiatric Association: Arlington, VA, USA, 2013.

45. Wilkinson, S. Women with breast cancer talking causes: Comparing content, biographical and discursive analyses. Fem. Psychol. 2000, 10, 431-460. [CrossRef]

46. Ryan, G.W.; Bernard, H.R. Data management and analysis methods. In Handbook of Qualitative Research, 2nd ed.; Denzin, N.K., Lincoln, Y.S., Eds.; Sage: Thousand Oaks, CA, USA, 2000.

47. Braun, V.; Clarke, V. Using thematic analysis in psychology. Qual. Res. Psychol. 2006, 3, 77-101. [CrossRef]

48. Wallace, D.J.; Linker-Israeli, M.; Hallegua, D.; Silverman, S.; Silver, D.; Weisman, M.H. Cytokines play an aetiopathogenetic role in fibromyalgia: A hypothesis and pilot study. Rheumatology 2001, 40, 743-749. [CrossRef]

49. Brambilla, F.; Monteleone, P.; Maj, M. Interleukin-1B and tumor necrosis factor-alpha in children with major depressive disorder or dysthymia. J. Affect. Disord. 2004, 78, 273-277. [CrossRef]

50. Gabbay, V.; Klein, R.G.; Alonso, C.M.; Babb, J.S.; Nishawala, M.; De Jesus, G.; Gonzalez, C.J. Immune system dysregulation in adolescent major depressive disorder. J. Affect. Disord. 2008, 115, 177-182. [CrossRef]

51. Henje Blom, E.; Lekander, M.; Ingvar, M.; Asberg, M.; Mobarrez, F.; Serlachius, E. Pro-inflammatory cytokines are elevated in adolescent females with emotional disorders not treated with SSRIs. J. Affect. Disord. 2011, 136, 716-723. [CrossRef]

52. Miller, G.E.; Cole, S.W. Clustering of depression and inflammation in adolescents previously exposed to childhood adversity. Biol. Psychiatry 2012, 72, 34-40. [CrossRef] [PubMed]

53. Wolraich, M.; Felice, M.E.; Drotar, D. The Classification of Child and Adolescent Mental Diagnoses in Primary Care: Diagnostic and Statistical Manual for Primary Care (DSM-PC) Child and Adolescent Version; American Academy of Pediatrics: Elk Grove Village, IL, USA, 1996.

54. Pao, M.; Bosk, A. Anxiety in medically ill children and adolescents. Depress. Anxiety 2011, 28, 40-49. [CrossRef] [PubMed]

55. Axelson, D.A.; Birmaher, B. Relation between anxiety and depressive disorders in childhood and adolescence. Depress. Anxiety 2001, 14, 67-78. [CrossRef] [PubMed] 
56. Bsiri-Moghaddam, K.; Basiri-Moghaddam, M.; Sadeghmoghaddam, L.; Ahmadi, F. The concept of hospitalization of children from the view point of parents and children. Iran. J. Pediatr. 2011, 21, 201-208.

57. Angström-Brännström, C.; Norberg, A.; Jansson, L. Narratives of children with chronic illness about being comforted. J. Pediatr. Nurs. 2008, 23, 310-316. [CrossRef]

58. Herbuela, V.R.D.M.; de Guzman, F.S.; Sobrepeña, G.D.; Claudio, A.B.F.; Tomas, A.C.V.; Arriola-Delos Reyes, C.M.; Regalado, R.A.; Teodoro, M.M.; Watanabe, K. Knowledge, Attitude, and Practices Regarding Dengue Fever among Pediatric and Adult In-Patients in Metro Manila, Philippines. Int. J. Environ. Res. Public Health 2019, 16, 4705. [CrossRef]

59. Eiser, C.; Patterson, D.; Eiser, J.R. Children's knowledge of health and illness: Implications for health education. Child Care Health Dev. 1983, 9, 285-292. [CrossRef]

60. Matley, S.L.; Kendall, L.; Quirk, J.; Gibbs, J.L.; Parsons, J.M.; Hewison, J. Illness understanding in children and adolescents with heart disease. Heart 2000, 84, 395-397.

61. Birmaher, B.; Ryan, N.D.; Williamson, D.E.; Brent, D.A.; Kaufman, J.; Dahl, R.E.; Nelson, B. Childhood and adolescent depression: A review of the past 10 years, Part 1. J. Am. Acad. Child Adolesc. Psychiatry 1996, 35, 1427-1439. [CrossRef]

62. Leibenluft, E. Irritability in children: What we know and what we need to learn. World Psychiatry 2017, 16, 100-101. [CrossRef]

63. Garralda, M.E. Hallucinations and Mental Health in Children. Oruen CNS J. 2017, 2, 32-36.

64. Hofstede, G. Culture's Consequences: Comparing Values, Behaviors, Institutions and Organizations across Nations; Sage: Thousand Oaks, CA, USA, 2001.

65. Nemade, R.; Staats Reiss, N.; Dombeck, M. Sociology of Depression-Effects of Culture. 2015. Available online: https://www.mentalhelp.net/articles/sociology-of-depression-effects-of-culture/ (accessed on 23 July 2018).

66. Kirmayer, L.J.; Rousseau, C.; Guzder, J. Cultural Consultation: Encountering the Other in Mental Health Care; International and Cultural Psychology-Springer: New York, NY, USA, 2014.

67. Kirmayer, L.J. Psychopharmacology in a globalizing world: The use of antidepressants in Japan. Transcult. Psychiatry 2002, 39, 295-312. [CrossRef]

(C) 2019 by the authors. Licensee MDPI, Basel, Switzerland. This article is an open access article distributed under the terms and conditions of the Creative Commons Attribution (CC BY) license (http://creativecommons.org/licenses/by/4.0/). 